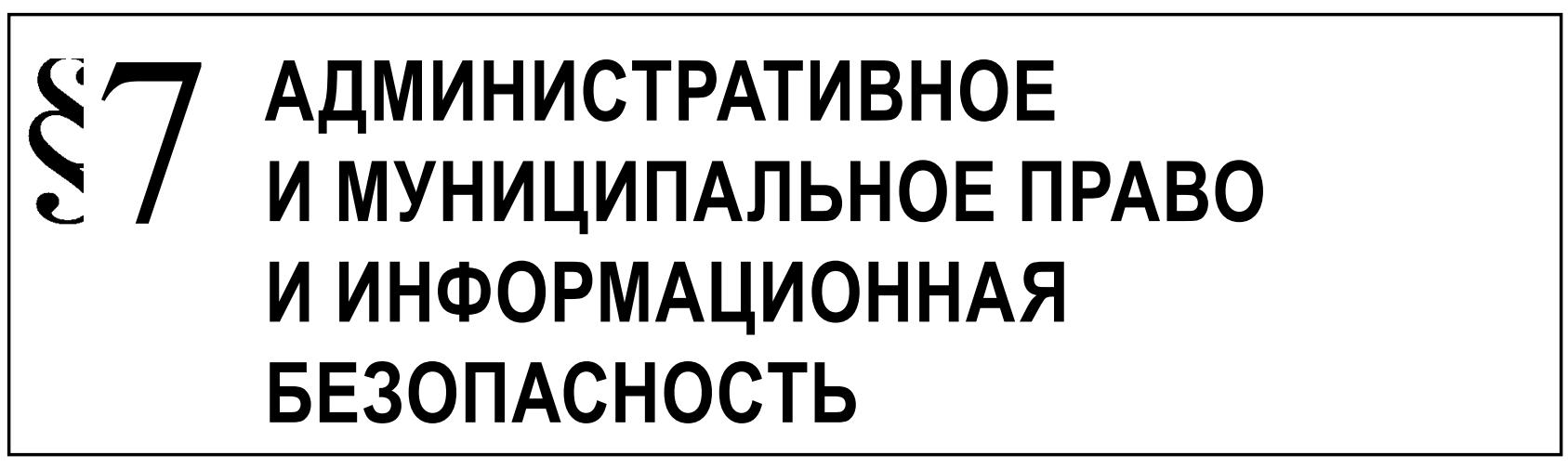

Амелин Р.В.

\title{
ОБЯЗАННОСТЬ ПО ПРЕДСТАВЛЕНИЮ ИНФОРМАЦИИ В ФЕДЕРАЛЬНЫЕ ИНФОРМАЦИОННЫЕ СИСТЕМЫ
}

\begin{abstract}
Аннотация. В статье рассматривается правовой статус поставщиков информации в государственные информационные системы, создаваемые на основе федеральных законов. Осуществляется попытка систематизации правовых норм, регулирующих отношения, связанные с представлением информации в такие информационные системы. Автор стремится к выделению правовых норм, которые могут быть унифицированы и включены в общую часть законодательства о государственных информационных системах. Также рассматриваются проблемы законодательства, связанного с отдельными информационными системами и предлагаются способы его совершенствования. Представленные наблюдения и выводы базируются на анализе правовых норм, регулирующих отношения по поводу 48 федеральных информационных систем, урегулированных в российском законодательстве на начало 2015 года. Предлагается унифицировать следующие элементы правового статуса поставщиков информации, вытекающие из обязанности по представлению информации в федеральные информационные системы: обязанность обеспечивать достоверность, полноту и актуальность представляемых им сведений; ответственность за непредставление информации, а также представление неполной, недостоверной информации или представление ее $c$ нарушением установленных сроков; право на исправление ошибки.
\end{abstract}

Ключевые слова: поставщик информации, государственная информационная система, достоверность информации, полнота информации, административная ответственность, исправление ошибки, государственное управление, представление информации, актуальность информации, большие данные.

Review. The article examines the legal status of information providers in Federal information systems. The author attempts to systematize the legal norms regulating the relations connected with the use of Federal information systems. The author outlines the legal norms which can be standardized and included in the General part of the Law on State information systems. It is proposed to unify the following elements of the legal status of information providers: duty to ensure accuracy, completeness and timeliness of information; responsibility for failure to provide information, as well as the submission of incomplete, false or incorrect information; the right to correct errors. The author also considers the problems of legislation, related to specific information systems, and offers the ways to improve it.

Keywords: public administration, error correction, administrative responsibility, completeness of information, correctness of information, state information system, information provider, provision of information, relevance of information, big data.

\section{Введение}

Поставщиком информащии в федеральную информационную систему является лицо, на которое возлагается обязанность предоставления информации для размещения в данной информационной системе в порядке, предусмотренном федеральным законом или принимаемым в соответствии с ним нормативными правовыми актами.

Рассмотрим элементы правового статуса этого специального субъекта информационного права, связанные с исполнением данной обязанности.
Под федеральной информационной системой (ФИС) будем понимать государственную информационную систему, созданную на основании федерального закона. Мы вынуждены уточнить неоднозначное определение п. 1 ч. 1 ст. 13 федерального закона от 27.07.2006 N 149-Ф3 «Об информации, информационных технологиях и о защите информации», поскольку оно допускает двоякое толкование и позволяет отнести к ФИС также системы, созданные на основании правовых актов федеральных государственных органов. Такие си- 


\section{Административное и муниципальное право 10 (94) 2015}

стемы не вошли в предмет настоящего исследования, хотя представляется что основные выводы, сделанные в работе, не утратили общности и могут быть распространены на отношения по поводу всех государственных информационных систем.

Представленные наблюдения и выводы базируются на анализе правовых норм, регулирующих отношения по поводу федеральных информационных систем, которых на начало 2015 года насчитывается около пятидесяти.

\section{Обязанность представления установленных законом сведений в установленные законом сроки}

Правовое регулирование отношений, связанных с использованием государственных информационных систем в настоящее время осуществляется довольно бессистемно. Однако в отличие от правового статуса пользователей информации и других элементов правового режима ИС, таких как цель создания, использование информации, требования к лингвистическим, техническим и программным средствам и пр., обязанность поставщиков информации по представлению сведений установлена для всех федеральных информационных систем. Действительно, информационная система, не имеющая источников информации, лишена всякого смысла.

Нам представляется, что на поставщиков информации, «внешних» по отношению к системе государственного управления (граждан, юридических лиц, органы местного самоуправления) обязанность по представлению информации в государственные информационные системы должна возлагаться на основании федерального закона. В подзаконных нормативных актах Правительства РФ или уполномоченных органов исполнительной власти данная обязанность может конкретизироваться. Например, уточняются сроки и периодичность представления информации, данные, образующие соответствующие категории сведений и т.д.

Многие информационные системы носят комплексный характер, в них хранятся и обрабатываются сведения из различных источников. Для таких информационных систем в нормативных актах должно быть установлено соответствие между информацией и ее поставщиками. С точки зрения юридической техники эта норма идеально сформулирована для ФИС ГИА. В п. 11 и 12 Правил формирования и ведения этой системы приводится перечень сведений, причем по каждому пункту указывается лицо, на которое возложена обязанность по их представлению, а также сроки и периодичность размещения информации. Например, «форма государственной итоговой аттестации, перечень учебных предметов, выбранных для сдачи государ- ственной итоговой аттестации (сведения вносятся образовательной организацией, реализующей общеобразовательные программы, ежегодно, до 5 марта)» [1]. Представляется неясным, почему эта простая модель не используется в отношении иных федеральных информационных систем.

Например, в Правилах представления информации в государственную информационную систему топливно-энергетического комплекса (ГИС ТЭК) установлены сроки исправления недостоверной информации, обнаруженной в системе, но сроки представления информации не указаны [2]. В соответствии с Правилами, информация должна представляться по специальным формам, которые размещаются уполномоченным органом на своем официальном сайте в сети «Интернет» вместе с требованиями по их заполнению. Так, в 2015 году были утверждены формы «Сведения о гидрометеорологическом обеспечении отраслей экономики за год» и «Сведения о гидрометеорологическом обеспечении отраслей экономики за месяц», в которых определены сведения, представляемые Росгидрометом, но указание на сроки в этих формах отсутствует [3].

По нашим оценкам, в отношении 22\% федеральных информационных систем сроки представления информации никак не обозначены. Они могут быть определены исходя из характера соответствующих сведений и документов. Например, упомянутые выше формы, очевидно, должны заполняться в разумное время по окончании соответствующего периода, но кто будет определять это разумное время и по истечении какого срока обязанность поставщиков информации следует считать неисполненной?

Сроки могут устанавливаться непосредственно федеральным законом. Например, в соответствии с ч. 4 ст. 12 Федерального закона от 01.07.2011 N 170-Ф3 «0 техническом осмотре транспортных средств и о внесении изменений в отдельные законодательные акты Российской Федерации», сведения, указанные в ч. 3 ст. 12, передаются оператором технического осмотра в единую автоматизированную информационную систему технического осмотра не позднее чем в течение суток с момента окончания проведения технического осмотра. Доля таких информационных систем, по нашим оценкам, составляет $17 \%$ от общего числа. Чаще сроки устанавливаются подзаконными нормативными актами - Постановлениями Правительства РФ (36\%) или нормативными актами оператора информационной системы (17\%). Возможны отсылки к иным источникам. Так, сроки представления информации в государственную систему миграционного учета сроки устанавливаются соглашением поставщика сведений с оператором информацион- 
ной системы (ч. 6 Постановления Правительства РФ от 14.02.2007 N 94 «0 государственной информационной системе миграционного учета»).

При определении сроков регулятор нередко использует категорию «незамедлительно» («в масштабе времени, близком к реальному» и т.п.). Чаще всего это характерно для систем, в которые информация передается в автоматическом режиме посредством специализированных программных средств. В иных случаях «незамедлительно» может быть интерпретировано следующим образом: поставщик должен приступить к исполнению обязанности по представлению информации сразу после возникновения такой информации. Данная категория может быть предложена как вариант «по умолчанию» для внесения определенности в правоотношения, связанные с использованием $22 \%$ ФИС с отсутствующими сроками. С этой целью соответствующее положение необходимо включить в «общую часть» института федеральных информационных систем, например, в закон «Об информации, информационных технологиях и о защите информации». Таким образом закроется, к примеру, пробел с реестром запрещенных сайтов (ст. 15.1 Ф3 «Об информации...»), для которого не установлен срок направления оператору информационной системы решения суда о включении доменного имени или сетевого адреса в реестр.

\section{Обязанность обеспечить полноту и достоверность представляемой информации}

Достоверность информации и своевременность ее представления отнесены к основным принципам правового регулирования отношений, возникающих в сфере информации, информационных технологиях и о защите информации (п. 6 ст. 3 Ф3 «Об информации...»). В соответствии с этим принципом, а также принципами, специально установленными в отношении отдельных федеральных информационных систем (например, принцип достоверности, полноты и актуальности сведений, содержащихся в государственном адресном реестре [4, п. 2 ст. 3]), на участников информационного взаимодействия может быть возложена обязанность обеспечить достоверность информации, размещенной в таких информационных системах. Поставщик информации несет ответственность в отношении представляемых им сведений, а оператор информационной системы обеспечивает их целостность уже в процессе использования.

Данная обязанность представляется нам универсальной, то есть, распространяющейся на всех поставщиков информации. Однако лишь для одной трети федеральных информационных систем она установлена в явном виде (причем, в ряде случаев только на уровне подзаконных нормативных актов). А в отношении федеральных государственных информационных систем «Мониторинг деятельности контрольно-надзорных органов» и «Мониторинг лицензирования отдельных видов деятельности» установлено, что поставщики информации осуществляют «мониторинг полноты, достоверности и актуальности размещенных ими сведений» [5, п. 11; 6, п. 10]. Если понимать эту норму буквально, то поставщики информации (государственные органы, осуществляющие соответствующие полномочия) получают особую форму индульгенции: можно представить недостоверную или неполную информацию, лишь констатировав это обстоятельство. Полагаем, что законодатель не имел этого в виду, но использовал технически некорректную формулировку.

Принцип полноты (и соответствующая обязанность) является менее однозначным. Он может трактоваться двояко. Во-первых, как полнота информации в ФИС. Это скорее идеал, к которому стоит стремиться, чем показатель, которого легко добиться. Даже для прекрасно зарекомендовавшей себя и имеющей многолетнюю практику эксплуатации системы ГАС «Выборы» полнота информации оказывается недостижимой. Так, по оценкам В. Е. Чурова, погрешность списка избирателей в Российской Федерации составляет 300 тыс. человек, что является очень хорошим показателем на 110 млн. избирателей, но говорить о полноте позволяет лишь условно [7, с. 16].

Во-вторых, можно говорить о полноте информации, представленной поставщиком. Здесь свойства полноты и достоверности оказываются взаимосвязанными. Дело в том, что отсутствие сведений о некотором факте может восприниматься не как неопределенность, а как отрицательная информация [8] (жестко заданные алгоритмы информационной системы и регламенты использования информации в государственных органов тому способствуют). Например, если нотариус не внесет в Единую информационную систему нотариата сведения об открытии наследства, пользователь информационной системы, запросивший такие сведения, будет считать, что наследственное дело не заведено (до тех пор, пока это не противоречит иной имеющейся у него информации). Соответственно, не представив в установленные сроки часть требуемых сведений, поставщик информации вводит в заблуждение будущих пользователей. Таким образом, обязанность обеспечить полноту информации также должна быть закреплена как часть правового статуса всех без исключения поставщиков информации в государственные информационные системы.

Чтобы добиться полноты и достоверности информации в федеральных ИС, необходимы обе- 


\section{Административное и муниципальное право 10 (94) 2015}

спечительные меры, а именно, установление ответственности за нарушение поставщиком информации его обязанностей. При определении характера и степени такой ответственности, необходимо учитывать цели создания информационной системы и способы использования хранящейся в ней информации.

Если информационная система обеспечивает ведение некоторого государственного реестра, каждая запись в котором имеет юридическое значение и удостоверяет юридически значимые обстоятельства (наделяющие правами и обязанностями, освобождающие от них), то полнота и достоверность информации являются наиболее критичными свойствами такой системы. Не случайно статьей 285.3 УК РФ установлена уголовная ответственность за фальсификацию единых государственных реестров. В работе [9] мы отстаиваем необходимость расширения предмета данной статьи на все ФИС, в которых хранится юридически значимая информация. Пробелы и неточности в базах данных единой государственной информационной системы обеспечения транспортной безопасности (ЕГИС ОТБ) могут препятствовать осуществлению мер по обеспечению транспортной безопасности (ч. 1 ст. 11 Федерального закона от 09.02.2007 N 16Ф3 «О транспортной безопасности»). Не поступившая вовремя в государственную информационную систему о государственных и муниципальных платежах (ГИС ГМП) информация о платежах может привести к отказу в получении государственной услуги. Для обеспечения стабильности соответствующих правоотношений требуется обязательное установление ответственности поставщиков информации за нарушение их обязанностей.

В то же время ряд федеральных информационных систем создаются в целях «информационного обеспечения» некоторой управленческой деятельности, при этом то, как именно должны использоваться накопленные сведения, в нормативных актах не закреплено. Определены лишь группы пользователей информации и категории сведений, которые им предоставляются. Другими словами, государство накапливает информацию впрок, справедливо оценивает ее как ценный ресурс, но пока еще не располагает аналитическим слоем технологиями, которые могли бы извлечь из этого ресурса практический результат. Такая парадигма называется «большими данными» и считается, что она имеет огромный потенциал в государственном управлении [10].

Традиционные подходы к анализу данных базировались на обработке определенной выборки (к которой предъявлялись особые требования, в частности, репрезентативности). Подход больших данных подразумевает, что выборкой должен стать весь массив данных в интересующей нас области. Мы анализируем не поведение выбранных по каким-то критериям представителей целевой группы, мы анализируем поведение всей группы. Нас интересуют не статистические данные (сумма дневной выручки демонстратора фильмов), а сведения о каждом проданном билете. Возможности современных ЭВМ и устройств хранения данных это позволяют.

Второй характерной особенностью новой парадигмы является отказ от точности в пользу полноты. Для успешной работы классических статистических методов, предъявлялись повышенные требования к качеству данных, входящих в выборку. Небольшая неточность серьезно влияла на качество результата. При работе с большими данными любая неточность несущественна, поскольку ее значение в общем объеме данных ничтожно. Это значит, что неизбежная потеря отдельных данных или их искажение (по техническим причинам или по вине человеческого фактора) не повлияет на результат обработки информации [11]. Как следствие, поставщикам информации в такие системы может быть предоставлено право на ошибку, поскольку единичные неумышленные погрешности в представляемых сведений не повлияют на результаты обработки данных в таких системах. Ответственность должна быть соразмерна общественной опасности деяния, в связи с чем мы категорически не согласны с гипертрофированной величиной штрафа, установленного статьей 19.7.7 за непредоставление или неполное предоставление демонстратором фильма, осуществляющим платный показ фильма в кинозале, информации в единую автоматизированную информационную систему сведений о показах фильмов в кинозалах (ЕАИС) либо предоставление заведомо недостоверной информации (от 100 до 400 тысяч рублей и от 400 до 800 тысяч рублей за повторное совершение правонарушения).

Таким образом, с одной стороны обязанность обеспечить полноту, достоверность (и своевременность) представления информации должна быть, по нашему мнению, универсальной и распространяться на всех поставщиков информации в федеральные информационные системы. Соответствующая норма должна быть внесена в федеральный закон «Об информации...». С другой стороны, следует учитывать, что для некоторых информационных систем полнота и достоверность информации объективно являются хотя и желательными, но не абсолютно необходимыми свойствами, а небольшие погрешности не скажутся на качестве решений, принятых на основе такой информации. С одной стороны, рассматриваемая обязанность должна обеспечиваться реальной ответственностью, а с другой стороны мера этой ответствен- 
ности должна определяться исходя из характера этих сведений и самой системы, нужна «тонкая настройка» (тем более, с учетом наметившейся тенденции законодателя требовать внедрения все большего числа информационных систем). Кроме того, поставщику должно быть предоставлено право на исправление ошибки.

\section{Право на исправление ошибки}

Добросовестный поставщик информации, обнаруживший ошибку при представлении информации в систему (вызванную сбоем технического оборудования, человеческим фактором или неполнотой/недостоверностью информации, имеющейся у самого поставщика на момент предоставления), должен иметь возможность её исправить. Такая возможность должна предоставляться как технически (функционалом информационной системы), так и организационно (закрепленным в нормативных правовых актах регламентом представления информации в систему).

Право на своевременное исправление ошибки добросовестным поставщиком соответствует принципу полноты и достоверности информации в государственных информационных системах и позволяет поставщикам информации эффективно исполнять возложенные на них обязанности.

В позитивном законодательстве право на исправление ошибки и порядок такого исправления предусмотрены лишь для 7 из 48 рассмотренных нами федеральных информационных систем. Так, «допускается внесение изменений в информацию, содержащуюся в системе учета древесины, при исправлении технических ошибок, а также при изменении сведений, ранее внесенных в систему учета древесины, если эти изменения произошли в случаях, предусмотренных законодательством Российской Федерации» [12, п. 6].

Более того, в отношении ЕАИС законодатель явно ограничил поставщика информации в этом праве: «Уточнение информации о киносеансе допускается только в отношении билетов, по которым был произведен возврат денежных средств» $[13$, п. 6]. Представляется, что причины указанного ограничения кроются в функциональных возможностях системы, что, на наш взгляд, недопустимо. Стоит, конечно, отметить, что информация вводится в эту систему не вручную поставщиком (демонстратором фильмов), а специальными программными средствами в автоматизированном режиме, но ответственность в соответствии со статьей 19.7.7 КоАП РФ наступает у демонстратора именно за внесение в систему недостоверной информации, а не за нарушение обязанности по установке таких программных средств [см. 14, 15].
В ряде случаев инициатива по исправлению ошибки в соответствии с регламентом может принадлежать не поставщику информации, а оператору системы. Так, в соответствии с регламентом ГИС ТЭК, уполномоченный орган при обнаружении недостоверной информации направляет в 2-дневный срок письменное уведомление об этом субъектам системы, предоставившим эту информацию. В свою очередь, такие субъекты в целях обеспечения своевременного внесения в нее исправлений в течение 5 рабочих дней после обнаружения этих фактов самостоятельно или после получения письменного уведомления от уполномоченного органа предоставляют в уполномоченный орган достоверную информацию с обоснованием внесения соответствующих исправлений [16, п. 5]. Такая модель правового регулирования представляется нам наиболее эффективной.

При этом поставщик информации в государственную информационную систему должен освобождаться от ответственности за неумышленное предоставление недостоверной информации, если он своевременно принял меры по исправлению такой ошибки. Исключение из этого правило удачно сформулировано в отношении единой государственной автоматизированной информационной системы учета объема производства и оборота этилового спирта, алкогольной и спиртосодержащей продукции (ЕГАИС): «Основанием для отказа организации в уточнении информации, содержащейся в единой информационной системе, является выявление территориальным органом или уполномоченным таможенным органом недостоверной и (или) искаженной информации, представленной этой организацией, либо наличие сведений о проверке, проводимой Федеральной службой по регулированию алкогольного рынка, ее территориальными органами или правоохранительными органами в отношении организации, и о налоговой проверке» [17, п. 10.3]. Представляется, что данный опыт уместно распространить и на иные федеральные информационные системы.

\section{Ответственность за представление неполной или недостоверной информации, за несвоевременное представление информации}

Ответственность поставщиков информации формально декларируется для 17 из 48 федеральных информационных систем (35\%). Реальная ответственность установлена лишь для 10 из них (21\%). Непредставление сведений (либо представление неполных, недостоверных, неактуальных сведений) значится в диспозиции статей 7.30, 7.31, 7.32.3, 8.28.1, 13.19.1, 14.4.1, 19.7.7, 19.7.9 КоАП РФ. 


\section{Административное и муниципальное право 10 (94) 2015}

В статьях 14.19, 14.51, 14.54, 14.60 КоАП РФ используются более общие формулировки, например, «нарушение установленного порядка проведения специальной оценки условий труда», который включает обязанность представления информации в систему.

Все перечисленные статьи используют формальный состав административного правонарушения.

Единственной информационной системой, для которой ответственность дифференцируется по форме вины (умысел или неосторожность) является ЕГИС ОТБ (ст. 19.7.9 КоАП РФ).

Если для одних систем ответственность поставщиков информации явно завышена, то для большинства она не предусмотрена вовсе, что приводит к неисполнению обязанностей. Эта проблема характерна также для многих государственных реестров (многие из которых ведутся без использования автоматизированных средств традиционными «бумажными» технологиями и не рассматриваются нами как информационные системы в соответствии с определением в законе «Об информации»). Так, в литературе неоднократно высказывается мысль о необходимости ввести ответственность кадастровых инженеров за допущенные ошибки при формировании объектов землеустройства, поскольку остро стоит проблема обеспечения достоверности информации о земельных участках $[18$, с. $79 ; 19$, с. 200].

В том случае, если сведения должны представляться в систему не напрямую, а направляться в уполномоченный орган (оператору системы), то за их непредставление или несвоевременное представление, либо представление в неполном объеме или в искаженном виде административная ответственность может наступать по статье 19.7 КоАП РФ. Наказание, установленное данной статьей представляется нам вполне соразмерным правонарушению и вполне оправданным для общего случая.

Статья 19.7 не учитывает проблематику государственных информационных систем и формально касается лишь представления информации в органы, осуществляющие государственный контроль (надзор), муниципальный контроль. Таким образом, непредставление сведений в ФИС «Федеральный реестр сведений о документах об образовании и (или) о квалификации, документах об обучении» попадает под диспозицию данной нормы, а в систему государственного информационного обеспечения в области торговой деятельности уже нет, поскольку у ее оператора - Министерства промышленности и торговли РФ - контрольно-надзорные полномочия отсутствуют.

По нашему мнению, диспозицию статьи 19.7 следует дополнить словами, «а также непред- ставление или несвоевременное представление сведений, представление которых предусмотрено законом в целях формирования и ведения государственных информационных систем, либо представление таких сведений в неполном объеме или в искаженном виде». Впоследствии, в случае реабилитации в информационном законодательстве РФ понятия «государственных информационных ресурсов», формирование и ведение которых как раз и обеспечивается посредством государственных информационных систем, государственные информационные системы в предлагаемой нами формулировке могут быть заменены на государственные информационные ресурсы.

В отношении отдельных информационных систем может устанавливаться специальная ответственность, как это и имеет место в текущем законодательстве. Нам представляется наиболее важным урегулировать меры ответственности для таких федеральных информационных систем как Единая информационная система нотариата, Федеральная информационная адресная система, Федеральная государственная информационная система территориального планирования, ФИС «Федеральный реестр апостилей, проставленных на документах об образовании и (или) о квалификации» и ряда других важных систем, полнота, достоверность и актуальность сведений в которых в настоящее время не имеет достаточного правового обеспечения. Что касается ЕАИС, то как отмечалось выше, особые меры ответственности, установленные для поставщиков информации в эту систему статьей 19.7.7 КоАП РФ представляются нам необоснованными и данную статью мы предлагаем исключить.

Более обоснованным, на наш взгляд, было бы установление ответственности за неисполнение обязанности по установке специализированных программных средств, предназначенных для представления информации в систему в автоматическом режиме (если именно такой способ предусмотрен для данной ФИС) или использование программных средств, не отвечающих установленным требованиям. Неисполнение этой обязанности означает, что поставщик информации не вносит в ФИС требуемые сведения постоянно и систематически (по причине отсутствия технической возможности).

\section{Выводы}

Правовой статус поставщиков информации является неотъемлемым элементом правового режима государственных информационных систем. Между тем, единый подход к правовому регулированию этого статуса отсутствует, в отношении разных информационных систем закрепляются различные 
права и обязанности поставщиков информации, некоторые важные аспекты зачастую упускаются регулятором из виду. Необходима систематизация и унификация нормативной базы в данной сфере.

Нам представляется, что находящийся на ранних этапах своего становления институт государственных информационных систем будет включать в себя общую часть, содержащую правовые нормы, общие для всех таких систем и особенную часть, относящуюся к правовому регулированию конкретных информационных систем. В рамках данной работы нами выделены следующие положения, которые необходимо вынести в общую часть и распространить на все государственные информационные системы:

1. Поставщик информации обязан представлять сведения, необходимые для ведения государственной информационной системы в установленные законом сроки.
2. Поставщик информации обязан обеспечивать достоверность, полноту и актуальность представляемых им сведений.

3. За непредставление информации, необходимой для ведения государственной информационной системы, а также представление неполной, недостоверной информации или представление ее с нарушением установленных сроков поставщик информации несет ответственность в соответствии с законодательством РФ. Меры ответственности должны быть соразмерны и устанавливаться с учетом назначения конкретной информационной системы, а также характера и юридического значения представляемых в нее сведений.

4. Поставщику информации должно быть предоставлено право на своевременное исправление ошибки при представлении сведений в государственные информационные системы.

\section{Библиография:}

1. Постановление Правительства РФ от 31.08.2013 N 755 «0 федеральной информационной системе обеспечения проведения государственной итоговой аттестации обучающихся, освоивших основные образовательные программы основного общего и среднего общего образования, и приема граждан в образовательные организации для получения среднего профессионального и высшего образования и региональных информационных системах обеспечения проведения государственной итоговой аттестации обучающихся, освоивших основные образовательные программы основного общего и среднего общего образования» // СЗ РФ, 09.09.2013, N 36, ст. 4583.

2. Постановление Правительства РФ от 22.12.2012 N 1384 «Об утверждении Правил предоставления в обязательном порядке субъектами государственной информационной системы топливно-энергетического комплекса информации для включения в эту систему» // СЗ РФ, 31.12.2012, N 53 (ч. 2), ст. 7940.

3. Приказ Минэнерго России от 20.02.2015 N 76 «Об утверждении форм предоставления в обязательном порядке Росгидрометом информации для включения в государственную информационную систему топливно-энергетического комплекса и требований к заполнению этих форм» // Официальный интернет-портал правовой информации http://www.pravo.gov.ru, 25.03.2015.

4. Федеральный закон от 28.12.2013 N 443-Ф3 «0 федеральной информационной адресной системе и о внесении изменений в Федеральный закон «Об общих принципах организации местного самоуправления в Российской Федерации» // СЗ РФ, 30.12.2013, N 52 (часть I), ст. 7008.

5. Постановление Правительства РФ от 27.12.2012 N 1443 «Об утверждении Правил формирования и ведения федеральной государственной информационной системы «Мониторинг деятельности контрольно-надзорных органов» // СЗ РФ, 07.01.2013, N 1, ст. 39.

6. Постановление Правительства РФ от 28.01.2013 N 52 «Об утверждении Правил формирования и ведения федеральной государственной информационной системы «Мониторинг лицензирования отдельных видов деятельности» // СЗ РФ, 04.02.2013, N 5, ст. 394.

7. Чуров В. Е. Развитие электронных технологий в избирательной си-стеме Российской Федерации // Право цифровой администрации в России и во Франции / Сборник научных материалов российско-французской международной конференции. 27-28 февраля 2013 года. - М.: ИГП РАН, Изд-во «Канон+» РООИ «Реабилитация», 2014. С. 16.

8. Амелин Р. В., Конобеевская И. М. Достоверность отрицательной информации о деятельности государственных органов и органов местного самоуправления // Хозяйство и право. 2010. - № 8. - С. 95-99.

9. Амелин Р. В. Внесение в единые государственные реестры заведомо недостоверных сведений: предмет преступления // Уголовное право. 2015. - № 1. - С. 4-8.

10. Виталий Мосеев. Большие данные: новые возможности для госсектора // CNews [Электронный pecypc]. URL: http://www.cnews.ru/reviews/new/ikt_v_gossektore_2014/articles/bolshie_dannye_novye_vozmozhnosti_dlya_ gossektora/ (дата обращения: 1.05.2015).

11. Майер Шенбергер, В. Большие данные. Революция, которая изменит то, как мы живем, работаем и мыслим / Виктор Майер Шенбергер, Кеннет Кукьер; пер. с агнл. Инны Гайдюк. - М.: Манн, Иванов и Фербер, 2014.

12. Постановление Правительства РФ от 03.12.2014 N 1301 «Об утверждении Правил представления информации в единую государственную автоматизированную информационную систему учета древесины и сделок с ней» // СЗ РФ, 15.12.2014, N 50, ст. 7090.

13. Постановление Правительства РФ от 18.10 .2010 N 837 «О функционировании единой федеральной автоматизированной информационной системы сведений о показе фильмов в кинозалах» // С3 РФ, 25.10.2010, N 43, ст. 5508. 


\section{Административное и муниципальное право 10 (94) • 2015}

14. Амелин Р. В., Чаннов С. Е. Об административной ответственности при представлении информации в государственные информационные системы // Информационное право. 2015. - № 1. С. 35-41.

15. Снегирев А.Г. Сведения о показах фильмов в кинозалах для ЕАИС // Автономные организации: бухгалтерский учет и налогообложение. 2010. - № 12. С. 68-72.

16. Постановление Правительства РФ от 22.12.2012 N 1384 «Об утверждении Правил предоставления в обязательном порядке субъектами государственной информационной системы топливно-энергетического комплекса информации для включения в эту систему» // СЗ РФ, 31.12.2012, N 53 (ч. 2), ст. 7940.

17. Постановление Правительства РФ от 25.08.2006 N 522 «0 функционировании единой государственной автоматизированной информационной системы учета объема производства и оборота этилового спирта, алкогольной и спиртосодержащей продукции» // С3 РФ, 04.09.2006, N 36, ст. 3830.

18. Нигматулина Э.Ф. О некоторых проблемах землеустройства на современном этапе // Аграрное и земельное право. 2012. № 7 (91).

19. Позднякова Е.А. Информационное обеспечение гражданского оборота земельных участков // Демократические институты в условиях развития информационного общества / Отв. ред. И.Л. Бачило. Сб. науч. работ. - М.: ИГП РАН - Изд-во «Канон+» РООИ «Реабилитация», 2014.

20. Соколова О.С. Административно-правовое регулирование муниципальных информационных отношений // Административное и муниципальное право. - 2010. - 9. - С. 85 - 91.

21. Комахин Б.Н. Информационное и инновационное общество и процесс развития государственной службы // NB: Административное право и практика администрирования. - 2014. - 1. - С. 32 - 45. DOI: 10.7256/23069945.2014.1.11155. URL: http://www.e-notabene.ru/al/article_11155.html

\section{References (transliterated):}

1. Postanovlenie Pravitel'stva RF ot 31.08.2013 N 755 «0 federal'noi informatsionnoi sisteme obespecheniya provedeniya gosudarstvennoi itogovoi attestatsii obuchayushchikhsya, osvoivshikh osnovnye obrazovatel'nye programmy osnovnogo obshchego i srednego obshchego obrazovaniya, i priema grazhdan v obrazovatel'nye organizatsii dlya polucheniya srednego professional'nogo i vysshego obrazovaniya i regional'nykh informatsionnykh sistemakh obespecheniya provedeniya gosudarstvennoi itogovoi attestatsii obuchayushchikhsya, osvoivshikh osnovnye obrazovatel'nye programmy osnovnogo obshchego i srednego obshchego obrazovaniya» // SZ RF, 09.09.2013, N 36, st. 4583.

2. Postanovlenie Pravitel'stva RF ot 22.12.2012 N 1384 «Ob utverzhdenii Pravil predostavleniya v obyazatel'nom poryadke sub"ektami gosudarstvennoi informatsionnoi sistemy toplivno-energeticheskogo kompleksa informatsii dlya vklyucheniya v etu sistemu» // SZ RF, 31.12.2012, N 53 (ch. 2), st. 7940.

3. Prikaz Minenergo Rossii ot 20.02.2015 N 76 «Ob utverzhdenii form predostavleniya v obyazatel'nom poryadke Rosgidrometom informatsii dlya vklyucheniya v gosudarstvennuyu informatsionnuyu sistemu toplivno-energeticheskogo kompleksa i trebovanii k zapolneniyu etikh form» // Ofitsial'nyi internet-portal pravovoi informatsii http://www.pravo. gov.ru, 25.03.2015.

4. Federal'nyi zakon ot 28.12.2013 N 443-FZ «O federal'noi informatsionnoi adresnoi sisteme i o vnesenii izmenenii v Federal'nyi zakon «Ob obshchikh printsipakh organizatsii mestnogo samoupravleniya v Rossiiskoi Federatsii» // SZ RF, 30.12.2013, N 52 (chast' I), st. 7008.

5. Postanovlenie Pravitel'stva RF ot 27.12.2012 N 1443 «Ob utverzhdenii Pravil formirovaniya i vedeniya federal'noi gosudarstvennoi informatsionnoi sistemy «Monitoring deyatel'nosti kontrol'no-nadzornykh organov» // SZ RF, 07.01.2013, N 1, st. 39.

6. Postanovlenie Pravitel'stva RF ot 28.01.2013 N 52 «Ob utverzhdenii Pravil formirovaniya i vedeniya federal'noi gosudarstvennoi informatsionnoi sistemy «Monitoring litsenzirovaniya otdel'nykh vidov deyatel'nosti»// SZ RF, 04.02.2013, N 5, st. 394.

7. Churov V. E. Razvitie elektronnykh tekhnologii v izbiratel'noi si-steme Rossiiskoi Federatsii // Pravo tsifrovoi administratsii v Rossii i vo Frantsii / Sbornik nauchnykh materialov rossiisko-frantsuzskoi mezhdunarodnoi konferentsii. 27-28 fevralya 2013 goda. - M.: IGP RAN, Izd-vo «Kanon+» ROOI «Reabilitatsiya», 2014. S. 16.

8. Amelin R. V., Konobeevskaya I. M. Dostovernost' otritsatel'noi informatsii o deyatel'nosti gosudarstvennykh organov i organov mestnogo samoupravleniya // Khozyaistvo i pravo. 2010. - № 8. - S. 95-99.

9. Amelin R. V. Vnesenie v edinye gosudarstvennye reestry zavedomo nedostovernykh svedenii: predmet prestupleniya // Ugolovnoe pravo. 2015. - № 1. - S. 4-8.

10. Vitalii Moseev. Bol'shie dannye: novye vozmozhnosti dlya gossektora // SNews [Elektronnyi resurs]. URL: http://www. cnews.ru/reviews/new/ikt_v_gossektore_2014/articles/bolshie_dannye_novye_vozmozhnosti_dlya_gossektora/ (data obrashcheniya: 1.05.2015).

11. Maier Shenberger, V. Bol'shie dannye. Revolyutsiya, kotoraya izmenit to, kak my zhivem, rabotaem i myslim / Viktor Maier Shenberger, Kennet Kuk'er; per. s agnl. Inny Gaidyuk. - M.: Mann, Ivanov i Ferber, 2014.

12. Postanovlenie Pravitel'stva RF ot 03.12.2014 N 1301 «Ob utverzhdenii Pravil predstavleniya informatsii v edinuyu gosudarstvennuyu avtomatizirovannuyu informatsionnuyu sistemu ucheta drevesiny i sdelok s nei» // SZ RF, 15.12.2014, N 50, st. 7090.

13. Postanovlenie Pravitel'stva RF ot 18.10 .2010 N 837 «O funktsionirovanii edinoi federal'noi avtomatizirovannoi informatsionnoi sistemy svedenii o pokaze fil'mov v kinozalakh» // SZ RF, 25.10.2010, N 43, st. 5508.

14. Amelin R. V., Channov S. E. Ob administrativnoi otvetstvennosti pri predstavlenii informatsii v gosudarstvennye informatsionnye sistemy // Informatsionnoe pravo. 2015. - № 1. S. 35-41. 
15. Snegirev A.G. Svedeniya o pokazakh fil'mov v kinozalakh dlya EAIS // Avtonomnye organizatsii: bukhgalterskii uchet i nalogooblozhenie. 2010. - № 12. S. 68-72.

16. Postanovlenie Pravitel'stva RF ot 22.12.2012 N 1384 «Ob utverzhdenii Pravil predostavleniya v obyazatel'nom poryadke sub"ektami gosudarstvennoi informatsionnoi sistemy toplivno-energeticheskogo kompleksa informatsii dlya vklyucheniya v etu sistemu» // SZ RF, 31.12.2012, N 53 (ch. 2), st. 7940.

17. Postanovlenie Pravitel'stva RF ot 25.08.2006 N 522 «O funktsionirovanii edinoi gosudarstvennoi avtomatizirovannoi informatsionnoi sistemy ucheta ob"ema proizvodstva i oborota etilovogo spirta, alkogol'noi i spirtosoderzhashchei produktsii» // SZ RF, 04.09.2006, N 36, st. 3830.

18. Nigmatulina E.F. O nekotorykh problemakh zemleustroistva na sovremennom etape // Agrarnoe i zemel'noe pravo. 2012. № 7 (91).

19. Pozdnyakova E.A. Informatsionnoe obespechenie grazhdanskogo oborota zemel'nykh uchastkov // Demokraticheskie instituty v usloviyakh razvitiya informatsionnogo obshchestva / Otv. red. I.L. Bachilo. Sb. nauch. rabot. - M.: IGP RAN - Izdvo «Kanon+» ROOI «Reabilitatsiya», 2014.

20. Sokolova O.S. Administrativno-pravovoe regulirovanie munitsipal'nykh informatsionnykh otnoshenii // Administrativnoe i munitsipal'noe pravo. - 2010. - 9. - C. 85 - 91.

21. Komakhin B.N. Informatsionnoe i innovatsionnoe obshchestvo i protsess razvitiya gosudarstvennoi sluzhby // NB: Administrativnoe pravo i praktika administrirovaniya. - 2014. - 1. - C. 32 - 45. DOI: 10.7256/2306-9945.2014.1.11155. URL: http://www.e-notabene.ru/al/article_11155.html 